\title{
Climate change and human impact in Macaronesia
}

\author{
José María Fernández-Palacios', S. Noguée, ${ }^{1}$, C. Criado ${ }^{4}$, S. Connor ${ }^{5}$, C. Góis-Marques ${ }^{6,7}$, M. Sequeira ${ }^{6}$ \\ and L. de Nascimento ${ }^{1}$
}

\section{Past climate dynamics have helped shape the endemic ecosystems of Macaronesia. However, these insular ecosystems have since been modified following the arrival of human settlers, who had to adapt to the new environments and resources.}

Macaronesia is a biogeographical region with four volcanic archipelagos (Azores, Madeira, Canaries and Cape Verde) in the NE Atlantic Ocean (Fig. 1). These island chains share several endemic genera and the three northernmost ones retain laurel forests, which are widely considered to be impoverished remnants of the Paleotropical Geoflora, distributed around the Tethys Sea during the Cenozoic, and disappeared at the onset of the Pleistocene glaciations.

Owing to their relatively late colonization by humans, oceanic islands offer the best conditions to disentangle the ecological impacts of human activities from those produced by climate shifts or volcanic events. Furthermore, Macaronesia comprises islands that were colonized either by North Africans (Canaries, ca. 2.9 ka BP; Atoche and Ramírez 2011) or later during the European expansion (Azores, Madeira and Cape Verde, 15th century; Fig. 1), allowing diverse cultural impacts to be differentiated. After their arrival, humans had to face and adapt to new environments and climatic conditions, which offered them new resources and provided new challenges.

\section{Past climate change}

The Canaries were subject to important climate change in the mid Holocene, namely the end of the African Humid Period, ca. 5.5 ka BP, which induced important shifts in the laurel forest composition, as the more hygrophilous taxa were displaced by more xerophilous ones (Nogué et al. 2013).

Paleoecological studies on Madeira Island are still rare, with the best contribution relating to the Piedade aeolian deposits (Goodfriend et al. 1996). An analysis of these deposits spanning the last 300 ka revealed changing plant cover through time, due to climate and sea-level shifts, as well as an abrupt change in vegetation following the arrival of the Portuguese.

On the Azores, paleoclimatic variations have been detected in sediments on Pico Island. Diatoms and geochemical indicators revealed several arid phases during the last 5000 years and an overall aridity trend linked to Atlantic sea-surface temperatures (Björck et al. 2006). However, vegetation on the Azores changed little in response to these climatic shifts (Connor et al. 2012).

Unfortunately, there are few paleoecological and paleoclimate studies in Cape Verde. Records from marine terraces, however, also point towards oceanic temperatures in this basin being warmer than the present ones during the Last Interglacial.

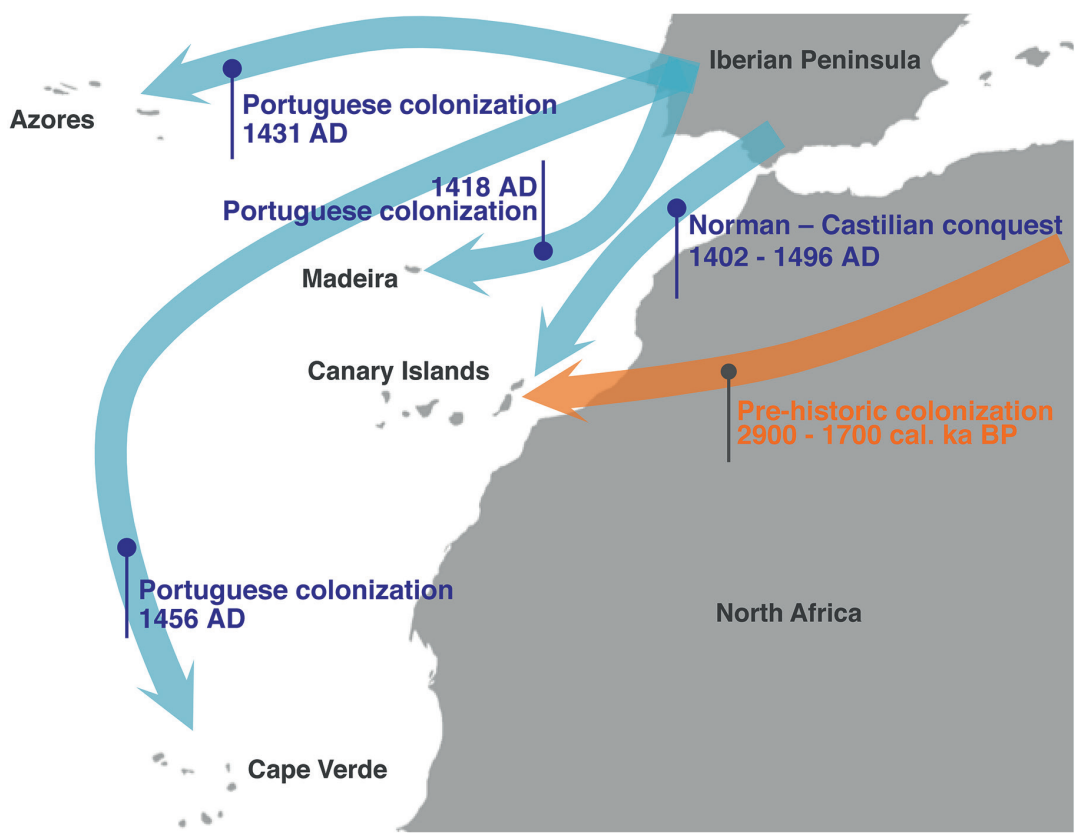

Figure 1: Human colonization of the islands of Macaronesia at prehistoric (orange arrow) and historical times (blue arrows).

\section{Human colonization, impact and adaptation}

The trade winds are lifted by the Canarian mountains, creating a year-round humid zone which provides the laurel forest with a refugium to withstand the summer aridity of the Mediterranean climate. This humid zone without analogue in North Africa during the Holocene, was an unknown environment for the arriving aborigines, where they found species offering new types of timber and fruits. Conversely, bronze or iron, known by early settlers, were not available in Macaronesia due to the volcanic origin of the islands; this led to a cultural decline to a level of the Stone Age (Atoche 2009).

During the pre-historic colonization, the aborigines introduced domestic species and used fire to clear forests and increase ecosystem productivity, hugely impacting the island biota that had evolved for more than $20 \mathrm{Ma}$ in the absence of humans. Ecological impacts included extinctions of plant (de Nascimento et al. 2009) and vertebrate (Rando 2003) species, and ecosystem transformations (de Nascimento et al. 2016).

Recent paleoecological work has revealed significant clearance of vegetation around $2.3 \mathrm{ka}$ BP that did not coincide with any known climatic shift or volcanic eruptions (de Nascimento et al. 2016), indicating that an aboriginal colonization of Gran Canaria must have taken place several centuries earlier than traditionally considered. We also know that there were forests in the highest parts of Fuerteventura, one of the driest islands in the Canaries, based on charcoal remains from trees used as firewood (Machado 2007) and fossil pollen records (de Nascimento, unpublished data). These forests formed under a more humid climate and have been able to subsist during the Late Holocene dry conditions (Yanes et al. 2011). After being cleared by aborigines, the much drier climate impeded the reestablishment of those forests resulting in the extirpation of several species of trees (Machado 2007) and the loss of a strategic wood resource for future generations.

\section{Changes following European settlement Since prehistoric times, humans have maximized the use of available resources at different elevations through the exploitation of coasts (saltworks, shellfishing), midlands (agriculture and forestry) and summits (green pastures, sulfur, ice collection; Aguilera et al. 1994), driving the altitudinal configuration}


Ice, sulfur, obsidian extraction
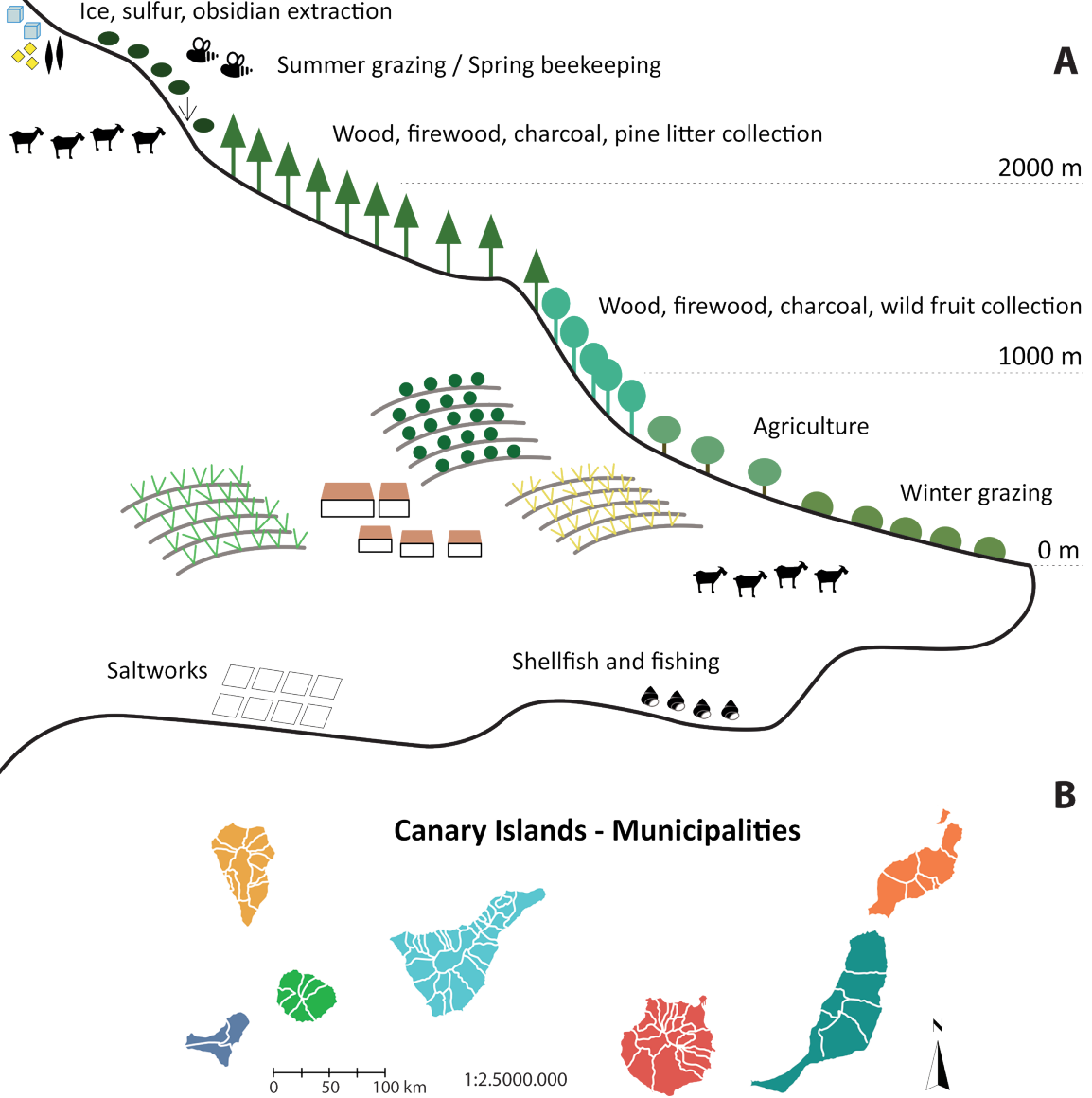

Figure 2: (A) Vertical exploitation of resources following the elevation gradient in Tenerife (Canary Islands; adapted from Aguilera et al. 1994), and (B) limits of the municipalities distributed from coast to summit in the Canary Islands.

of the present municipalities in Macaronesia (Fig. 2)

After the Castilian conquest of the Canaries (1402-1496 AD), the new society changed from a pastoral to an agricultural economic base, shifting the cultural impacts abruptly from species threats to deforestation, to provide firewood for sugar mills and land for sugarcane plantations, as well as timber for house and boat building. The archipelago also suffered severe droughts during the 17th and 18 th centuries, leading to starvation and massive migrations among islands (García et al. 2003).

Madeira or "Island of Wood" owes its name to the primeval forests that used to cover it, which provided an important source of woods for Portugal. Since Madeira's discovery in 1418 , documents show that the exploitation of the forests allowed the building of larger ships for the Portuguese navy (contributing to the expansion of the conquests) and even for the growth in height of Lisbon's buildings. The deforestation in Madeira was so fast that royal decrees from 1493 exist to limit it (Menezes de Sequeira et al. 2007).

The over-exploitation of forests, agriculture, fire and the introduction of alien species led to the extinction or extirpation of native species, such as rails (Rallus), the Porto Santo flora, and most probably unknown trees described in historical chronicles (Menezes de Sequeira et al. 2007).
On the Azores, the northernmost archipelago of Macaronesia, islands discovered by colonists that were suitable for growing European crops have since lost much of their original vegetation (e.g. Graciosa island), while the wettest, steepest parts of some islands have retained relatively intact vegetation (e.g. Flores island). Indeed, pollen records show that laurel and juniper forests were distributed at various elevations prior to human colonization (Connor et al. 2012). Historical reports attest to the density and diversity of this original vegetation, along with the presence of species that are now extinct on certain islands (e.g. Juniperus brevifolia and Taxus baccata). Human impacts were felt even before colonization began, with the release of livestock providing meat for future colonists (Schaefer 2003).

Although the Azorean vegetation was well adapted to recover from disturbances such as landslides and volcanic eruptions, human colonization caused irreversible changes, including the loss of forest trees, local extinctions and the creation of novel vegetation communities (Connor et al. 2012; Schaefer 2003). Timber felling, burning and various agro-pastoral monocultures have shaped the Azorean landscape since the time of colonization. Like many colonized islands, exotic plants today greatly outnumber native species on the Azores, and invasive species are a major threat to the island's native biodiversity (Schaefer 2003).
Finally, Cape Verde is the southernmost and only tropical archipelago of Macaronesia. It is thought to have been uninhabited when the Portuguese colonized it around 1462 AD (Heckman 1985). The first settlers and expeditions described the landscape as having reduced forest cover with a mix of tropical and temperate species. In addition, historians pinpointed that the earlier settlers likely mismanaged the natural resources of the islands and that no attempt was made to create self-sufficient colonies (Heckman 1985).

The primary function of the islands of Cape Verde for the first hundred years was to serve as a base for the slave trade. In addition, many ships stopped to resupply food and water. During the 15th and 16th centuries, large plantations raised cotton, coffee, maize, and sugar cane. During the 17th century, some islands successfully established livestock.

Despite paleoecological and paleoclimate research still in their initial phase in Macaronesia, it has already provided evidence for climate change and human interactions. We are sure that, in the near future, ongoing research of the human impacts on these archipelagos will significantly increase our understanding of colonization processes and cultural evolution.

\section{ACKNOWLEDGEMENTS}

We thank Claudia Ruiz for preparing Figure 2.

\section{AFFILIATIONS}

IIsland Ecology and Biogeography Group, Universidad de La Laguna, San Cristóbal de La Laguna, Spain ${ }^{2}$ Geography and Environment, University of Southampton, UK

${ }^{3}$ Department of Zoology, University of Oxford, UK ${ }^{4}$ Department of Geography and History, Universidad de La Laguna, San Cristóbal de La Laguna, Spain ${ }^{5}$ School of Geography, The University of Melbourne, Australia

${ }^{6}$ Madeira Botanical Group, University of Madeira, Funchal, Portugal

'Department of Geology, University of Lisbon, Portugal CONTACT

José María Fernández-Palacios: jmferpal@ull.es

\section{REFERENCES}

Aguilera F et al. (1994) Canarias. Economía, Ecología y Medio Ambiente. Francisco Lemus Editor, 361 pp Atoche P (2009) Zephyrus 63: 105-134

Atoche P, Ramírez MA (2011) An Estudios Atlánticos 57: 139-169

Björck S et al. (2006) Quat Sci Rev 25: 9-32

Connor SE et al. (2012) J Biogeogr 39: 1007-1023

de Nascimento L et al. (2009) J Biogeogr 36: 499-514 de Nascimento L et al. (2016) Holocene 26: 113-125 García R et al. (2003) B Am Meteorol Soc 81: 1037-1039 Goodfriend GA et al. (1996) Palaeogeogr Palaeocl

Palaeoecol 120: 195-234

Heckman J (1985) Environ Manage 9: 141-150

Machado MC (2007) Tabona 15: 71-90

Menezes de Sequeira et al. (2007) In: Silva J (Ed.) Árvores e Florestas de Portugal. Vol. 6 Açores e Madeira - A Floresta das Ilhas. Público, 165-196

Nogué S et al. (2013) J Ecol 101: 368-377

Rando JC (2003) El Indiferente 14: 4-15

Schaefer H (2003) Diss Bot 374: 1-130

Yanes Y et al. (2011) Quat Res 75: 658-669 